\title{
Migrant care workers in elderly care: what a study of media representations suggests about Sweden as a caring democracy
}

\author{
By SANDRA TORRES ${ }^{1} \mathcal{E}$ JONAS LINDBLOM ${ }^{2}$
}

\begin{abstract}
This article sheds light on the ways in which migrant care workers in the elderly care sector were represented in Swedish daily newspaper articles published between 1995 and $2017(n=370)$; it uses the notions of the "ethics of care" and "caring democracy" as a prism through which the findings can be made sense of. By bringing attention to the fact that they are often described as the solution par excellence to the staffing crisis Swedish elderly care is experiencing, this article draws attention to portrayals of these workers as people who are both particularly good at caring and capable of providing culture-appropriate care. Thus, although depicted as "particular Others," these workers are represented as an asset to the sector - a sector that is thought to offer much needed but highly undervalued services. By bringing attention to both of these representations, and using the theoretical and conceptual framework "ethics of care" formulated by Tronto, the article questions whether Sweden - a country often described as the epitome of an egalitarian society - can be regarded as a caring democracy.
\end{abstract}

Keywords: elderly care, ethics of care, media representations, migrant care workers, Sweden.

${ }^{1}$ Sandra Torres, Department of Sociology, Uppsala University, Sweden ${ }^{2}$ Jonas Lindblom, Division of Sociology, School of Health, Care and Social Welfare, Mälardalen University, Sweden 
International Journal of Ageing and Later Life

\section{Introduction}

Research has shown that media representations of ethnic minorities and migrants - often regarded as ethnic "Others" - influence ethnic majority members' perceptions of these groups (Ferguson 1998; Wood \& King 2001). This is because the media offer input to adult citizens' daily discussions, implying that the role of the media "as a prevailing discourse and attitude context for thought and talk about ethnic groups is probably unsurpassed by any other institutional or public source of communication" (van Dijk 1987: 41). From this, it follows that media representations play a role in how prejudices are taught and reproduced (cf. Brown 1995), as well as in facilitating populist sentiments (see, e.g. Gale 2004). It is against this backdrop that we set out to study Swedish media representations of migrant care workers in daily newspaper reporting on elderly care. Our interest is informed by the debate on the ethics of care, which suggests that studies of the care discourse can give us an insight into the moral fabric of a society. We believe that the ways in which daily newspapers write about migrant care workers could have implications for public opinion about them, as well as for the ways in which people come to regard the welfare sector, that is, elderly care.

The analyses presented here tap into the ways in which the globalization of international migration, and population aging, have heightened European societies' awareness of why care work cannot be relegated to the periphery of policy-making (Kilkey et al. 2010; Pfau-Effinger \& Rostgaard 2011; Torres 2006a, 2013). Long-term care systems' increasing reliance on migrant workers (e.g. Browne \& Braun 2008; Leeson 2010); the gendered, racial and ethical challenges that importing these workers entails (e.g. Bettio et al. 2006; Robinson 2006); and the care chains that are created by them (e.g. Hochschild 2000; Yeates 2004) are all issues that demand our attention. We have deemed it useful to rely on the debate on the ethics of care - which began in the early 1990s and was reignited some 6 or so years ago partly due to international migration and population aging (see, e.g. Barnes et al. 2015; Olthuis et al. 2014; Tronto 2010, 2013) - as the lens through which media representations of welfare sectors can be understood. 
Migrant care workers in elderly care

At the core of this debate (see, e.g. Tronto 1987, 2010, 2013) is the following argument:

Vulnerability belies the myth that we are autonomous, and potentially equal, citizens. To assume equality among humans leaves out and ignores important dimensions of human existence. Throughout our lives, all of us go through varying degrees of dependence and independence, of autonomy and vulnerability. (Tronto 1993: 135)

Besides bringing attention to the inevitability of our interdependence throughout the life course, the ethics of care debate has problematized how care regimes organize care work, what care work means to those who receive and provide it, as well as who is best suited to providing care and why (e.g. Barnes et al. 2015; Olthuis et al. 2014). In addition, care scholars have argued that relegating care to the periphery of the public sphere makes little sense, because one person's dependency can be the means through which another person asserts his/her autonomy (Robinson 2006). Against this backdrop, it is perhaps understandable that ethics of care scholars regard the organization of care as a complex set of power relationships.

Tronto (1993) made the following argument: "there is great ideological advantage to gain from keeping care from coming into focus. By not noticing how pervasive and central care is to human life, those who are in positions of power and privilege can continue to ignore and to degrade the activities of care and those who give care" (Tronto 1993: 111). It is against this backdrop that we set out to explore the media representations of migrant care workers that a Swedish daily newspaper has relied on since it first started reporting on the effects of globalization of international migration would have on the elderly care sector back in 1995. Narayan (1995) aptly expressed one of the reasons we deem this angle of investigation interesting:

[W]hile aspects of care discourse have the potential virtue of calling attention to vulnerabilities that mark relationships between different situated persons, care discourse also runs the risk of being used to ideological ends where these "differences" are defined in self-serving ways by the dominant and the powerful. (Narayan 1995: 136)

Thus, inspired by the ethics of the care debate, the present article's starting point is the assumption that studies that draw attention to care offer important 
International Journal of Ageing and Later Life

insights into a society's moral backbone (cf. Tronto 1995, 2010) as well as its relationship with "particular Others" (cf. Narayan 1995). This means that although we acknowledge that "care is not the only principle of modern moral life," we deem care discourse to be an interesting angle of investigation in our attempt to expose power relationships. To this end, it would seem necessary to point out that, in one of her latest contributions, Tronto argued that welfare states need to "figure out how to put responsibilities for caring at the center of their democratic political agendas" (2013: ix), and that only those who end up managing to do so can be regarded as caring democracies.

\section{Research on Migrant Care Workers}

Research on migrant care workers has slowly but surely gained momentum over the past two decades. The following are the angles of investigation that have received the most attention:

- Research on the policies that have opened the door to their recruitment as well as the policy implications that their recruitment has for the sector (e.g. Di Rosa et al. 2012; Lowell et al. 2010; Lutz \& Palenga-Möllenbeck 2010; Wall \& Nunes 2010)

- Studies that shed light on migrant care workers' migration motives (e.g. Raijman et al. 2003)

- Research that brings attention to the tasks they perform in different countries, and the conditions under which they work (e.g. Elrick \& Lewandowska 2008; Iecovich 2010)

- Studies that bring attention to the ways in which migrant care workers view their work and life situation (e.g. Doyle \& Timonen 2009; Doyle \& Timonen 2010; Iecovich 2011; McGregor 2007; Stevens et al. 2012; Timonen \& Doyle 2010; Walsh \& O'Shea 2010).

- Research that reveals the ways in which different stakeholders, and clients, regard these workers and the care they provide (e.g. Bourgeault et al. 2010; Iecovich 2007; Jönson 2007; Shutes \& Walsh 2012; Walsh \& Shutes 2012).

Few studies have brought attention to the ways in which public debates or daily newspaper reporting depicts migrant care workers. To the best of our knowledge, there seem to be two studies with this starting point: 
first, a study by Weicht (2010), which analyzed Austrian discourses on migrant caring by bringing attention to both newspaper articles and focus group discussions about these workers; second, a study by Nordberg (2016), which analyzed Finnish media representations of migrant care workers using data collected in collaboration with the present authors (as described below).

\section{Method}

The present article utilizes data generated from a comparative project of daily newspaper reporting on elderly care, which focuses on how ethnicity, culture, language, religion and migration-related issues are addressed in the major newspapers in Sweden and Finland between 1995 and $2017 .{ }^{1}$ The analysis begins with articles from 1995 because this is when public debates on the challenges associated with culture and ethnic diversity within the elderly care sector started in the countries the project focuses on. The sample for the Swedish part of the project, which we rely on here, includes all articles published in Svenska Dagbladet (SvD) and Dagens Nyheter (DN), the two Swedish daily newspapers with nationwide coverage $(N=370)$. In the present article, we focus primarily, though not exclusively, on the articles about migrant care workers. These articles constitute $44.4 \%$ (164) of the data corpus.

The analysis has been conducted in two phases. First, we conducted a quantitative analysis by taking into account the context the reporting brought attention to, the topics being discussed, whether the interest in migrant care workers had changed over time (which we refer to as the time angle), the resources associated with these workers, the actors being discussed (i.e. in relation to whom are migrant care workers being discussed?), who has participated in the discussion (which we refer to as the

\footnotetext{
1 This project has already generated some publications. For example, Torres et al. (2012) focused on country comparisons covering the period 1995-2008, while Torres et al. (2014) presented results covering the period 1995-2011. In addition, Lindblom and Torres (2011) presented results from the Swedish material covering the period 1995-2008, while Torres 2017 revealed how migrant care workers were described in a 3-page-long piece for a Special Issue of Sociologisk Forskning. In addition, and as already mentioned, Nordberg (2016) presented the ways in which Finnish newspapers have written about migrant care workers during the years 2003 and 2013.
} 
International Journal of Ageing and Later Life

participants), and the ethnic background of those who have been given the opportunity to express themselves in these newspaper articles. In order to systematize the analysis and create conditions for good reliability, we created a coding scheme (in which all coded data were registered) and a code book (describing the principles used when coding the data) (cf. Neuendorf 2002). The establishment of coding principles was important, because the newspaper material scrutinized seldom deals only with the relation between elderly care and issues of ethnicity/migration but often with other topics as well. In other words, an article can contain information that is not relevant to the project's aims, and in such cases, only parts of the content have been coded. It is also worth noting that, in order to ensure the reliability of the coding, we discussed how the codes should be delimited and how the coding principles would be used, throughout the entire coding process. Thus, the coding process involved close collaboration between three researchers (the two present authors and their Finnish colleague). This means that we relied on "peer-debriefing sessions" to guarantee the reliability of the quantitative analysis (Cresswell 1998).

The results of the quantitative analyses were used as a starting point for the qualitative analysis, which in relation to migrant care workers focused on the following two questions: How do the newspaper articles in question describe migrant care workers, and what assumptions do they make about them? This part of the analysis followed Bryman's (2006) guidelines for thematic content analysis. Thus, we looked for both the manifest and the latent meanings of words, expressions and longer excerpts to identify the underlying patterns in the newspaper material. This is why the qualitative analysis was carried out only after the quantitative analysis provided the necessary background data on the frequency of various patterns. The analysis followed, in other words, Silverman's (2001: 222) recommendation to start each study by asking basic "what" questions before going on to ask more advanced "how" questions. Thus, although the present article focuses primarily on the findings generated through the qualitative analysis, we will also refer to some of the findings generated by the quantitative analysis. Continuous comparison with the quantitative data served as an important reliability measure, helping us to avoid drawing conclusions that only capture isolated tendencies in the material. The analysis presented here is therefore the result of our active search for disconfirming evidence (cf. Silverman 2001). 
Migrant care workers in elderly care

\section{Findings}

Table 1 shows the topics that are primarily discussed in the newspaper articles that comprise the data corpus. The table shows that recruitment of migrant workers to the elderly care sector and deliverance of culture-appropriate care are the two main topics discussed in the data corpus.

Table 1 also shows that the topics receiving the most attention in the daily newspaper reporting referred to here focus on different elderly care actors. The recruitment of migrant care workers (which $44.4 \%$ of the data corpus focuses on) is mostly discussed from the angle of what migrants who are care providers have to offer $(40.3 \%$ of the articles on migrant care workers utilize this angle). This means that this is the one reason that was utilized most often in the data corpus. The topic of culture-appropriate care (which $42.3 \%$ of the articles focus on) is discussed from the perspectives of migrants who are care recipients $(29.2 \%$ of the articles on this issue take this perspective). Both of these topics are, thus, discussed from the perspective of the ethnic minority. In other words, the perspectives of those who constitute the majority of elderly care providers and

Table 1. Topics discussed in the data corpus in relation to the background of the elderly care actors in focus $(N=370)$

\begin{tabular}{|c|c|c|c|c|}
\hline \multirow{2}{*}{$\begin{array}{l}\text { Background of the } \\
\text { elderly care } \\
\text { actors in focus }\end{array}$} & \multicolumn{4}{|c|}{ Topics discussed } \\
\hline & $\begin{array}{l}\text { Recruitment of } \\
\text { migrant care } \\
\text { workers }(\%)\end{array}$ & $\begin{array}{l}\text { Culture- } \\
\text { appropriate } \\
\text { care }(\%)\end{array}$ & Other $(\%)$ & Total \\
\hline $\begin{array}{l}\text { Migrants as elderly care } \\
\text { recipients }\end{array}$ & $1.9 \%(7)$ & $29.2 \%(108)$ & $6.5 \%(24)$ & $37.6 \%(139)$ \\
\hline $\begin{array}{l}\text { Migrants as elderly care } \\
\text { providers }\end{array}$ & $40.3 \%(149)$ & $3.2 \%(12)$ & $3.5 \%(13)$ & $47 \%(174)$ \\
\hline Migrants as relatives & $0.3 \%(1)$ & $1.6 \%(6)$ & $0.3 \%(1)$ & $2.2 \%(8)$ \\
\hline $\begin{array}{l}\text { Non-migrants (or natives) } \\
\text { as elderly care recipients }\end{array}$ & $1.6 \%(6)$ & $7.8 \%(29)$ & $1.9 \%(7)$ & $11.3 \%(42)$ \\
\hline $\begin{array}{l}\text { Non-migrants (or natives) } \\
\text { as elderly care providers }\end{array}$ & $0.3 \%(1)$ & $0.5 \%(2)$ & $1.1 \%(4)$ & $1.9 \%(7)$ \\
\hline Total & $44.4 \%(164)$ & $42.3 \%(157)$ & $13.3 \%(49)$ & $100 \%(370)$ \\
\hline
\end{tabular}


International Journal of Ageing and Later Life

recipients (i.e. ethnic Swedes) are not in focus in this data corpus. Less than $8 \%$ of the articles on culture-appropriate care focus on nonmigrants, while only close to $2 \%$ of the articles focusing on migrant care workers focus on them.

Although not shown in Table 1, some of the articles focusing on migrant care workers are about hiring people with migrant backgrounds who are already in Sweden $(64.6 \%$ out of these 164 articles focus on settled immigrants), in contrast to importing migrants to the sector (only $22.6 \%$ of the articles focus on the actual import of workers to the sector). Thus, when we use the term "migrant care worker" here, we mean both those who have migrated in order to care and those who have ended up in the care sector after having migrated (often because they have failed to integrate into the Swedish society and have therefore not secured employment in other sectors).

\section{Migrant Care Workers as the Solution to the Labor Shortage in Elderly Care}

In order to understand how migrant care workers are portrayed in the data corpus, we need to consider that Swedish elderly care has been at a critical breaking point for at least two decades due to, among other things, population aging. Most of the articles report that the number of people over the age of 65 has dramatically increased and will continue to do so in the future, meaning there is and will be a shortage of staff. Two articles summarize the situation as follows:

There is a crisis again regarding the population issue in Sweden. The question of how we should take care of our elderly, our very own elderly, has a prominent place in the public debate. And its significance will grow. Just like the number of elderly in the population. (Article entitled "Immigration solves the crises" - "Invandring löser krisen" - published on November 1, 1998 in SvD)

$\&$

The claim has been made countless times in recent years: since Sweden's population is getting older, immigrants are needed to increase the number of people working. Instead of asking how much immigration Sweden can manage, the question should be how much immigration does Sweden need? Who else will take care of us when we get older? (Article entitled "How does immigration become profitable?" - "Hur blir invandring lönsamt?"- published on December 8, 2015 in SvD) 
The first article referred to here alludes to the fact that "there is a crisis again." This article refers to Swedish sociologists Gunnar and Alva Myrdal who, during the 1930s, discussed the serious consequences of a continued low birth rate in Sweden. The reference to the critical situation experienced in the past stresses the gravity of the present situation. This article proposes - as others do as well - that immigration is the answer to the crisis. Thus, the care that migrants can provide is referred to as one of the ways (in fact, the preferred way as we will see shortly) in which the elderly care sector can address the challenge of population aging. It is also worth noting that, although the solution discussed in these extracts involves importing migrants to the sector, this is not the only solution offered in this daily newspaper reporting. On the one hand, we have articles suggesting that the sector should recruit people with migrant backgrounds who are currently living in Sweden but are unemployed - that is, settled immigrants should be attracted to the sector. On the other hand, there are articles suggesting that, to solve the elderly care crisis, the welfare sector should attract people from abroad - that is, the sector should import staff and invest in labor migration schemes. Thus, in this newspaper reporting, Sweden is depicted as a country that not only needs migrants who can work and contribute to its economy but also as a country that needs migrants who can care for its aging population (see also Nordberg 2016, who shows a similar pattern in Finnish media representations). This resonates well with Tronto's (2013) argument regarding how a caring democracy is built. She argues that when societies regard care as something that "Others" are "naturally" good at or destined to do, they tend to "assign the responsibilities for caring to noncitizens /.../ and working-class foreigners" (Tronto 2013: 10). The media representations of migrant care workers referred to here argue this very thing, because they state that it makes perfect sense for migrants to take on the caring tasks the elderly care sector crisis has generated, now that population aging entails demographic changes in the Swedish population.

Table 2 shows that it is mostly economic, organizational and/or demographic reasons that are given to explain why recruitment of migrants to the elderly care sector is necessary. These reasons are utilized in $28.2 \%$ of the articles arguing that the Swedish elderly care sector needs to recruit migrant care workers. 
International Journal of Ageing and Later Life

Table 2. Topics in relation to the reasons alluded to $(n=370)$

\begin{tabular}{|c|c|c|c|}
\hline \multirow{2}{*}{$\begin{array}{l}\text { Reasons alluded to } \\
\text { when representing the topic }\end{array}$} & \multicolumn{2}{|c|}{$\begin{array}{l}\text { Topics depicted } \\
\text { (\% and actual number) }\end{array}$} & \multirow{2}{*}{ Total } \\
\hline & $\begin{array}{l}\text { Recruitment of } \\
\text { migrant care workers }\end{array}$ & Other topics & \\
\hline Culture-related reasons & $12.4 \%(46)$ & $38.9 \%(144)$ & $51.3 \%(190)$ \\
\hline $\begin{array}{l}\text { Economic, organizational } \\
\text { and/or demographic reasons }\end{array}$ & $28.2 \%(104)$ & $14.8 \%(55)$ & $43 \%(159)$ \\
\hline Other & $3.8 \%(14)$ & $1.9 \%(7)$ & $5.7 \%(21)$ \\
\hline Total & $44.4 \%(164)$ & $55.6 \%(206)$ & $100 \%(370)$ \\
\hline
\end{tabular}

Among the reasons alluded to are: the high ratio of unemployed migrants already living in Sweden, the growing elderly population, and ethnic Swedes' low motivation to work in the elderly care sector. However, the recurring idea many articles present is that migrants who are already living in Sweden are untapped resources because they already have some experience of Swedish society and customs (even of the welfare sector in some cases), which is why they should be regarded as an attractive labor force before importing migrants to the sector is considered. Importing migrants to the sector seems to be deemed more costly than attracting migrants who already live in Sweden. Furthermore, some newspaper articles point out that some migrants living in Sweden already have professional backgrounds that fit the needs of the elderly care sector. Finally, some of the articles mention that the social and economic problems migrants already living in Sweden face need to be solved before any further immigration can take place. The idea being that becoming employed in the elderly care sector is a step in the right direction for settled (but currently unemployed) migrants' integration. For instance, one of the articles analyzed stated:

Sweden has failed to take advantage of the "reserve army" made up of existing immigrants and refugees. As long as these people are shut out of the job market, possibilities for development and civic life, labor migration is surely impossible. It is morally difficult to imagine that Latvians, Romanians, Czechs and Ukrainians would be offered work in Sweden while Swedes with an immigrant background remain unemployed. And the popular resistance to large-scale immigration will no doubt continue to be significant 
Migrant care workers in elderly care

as long as today's problems related to the multi-ethnic Sweden remain. (Article entitled "Commentary - Wanted: visions and courage" - "Kommentaren - Efterlyses: visioner och mod" - published on March 22, 2000 in SvD)

In this excerpt, settled migrants are described as "a reserve army"; a resource into which the Swedish society, in general, and the elderly care sector, in particular, have yet to tap. This is not the only military allusion in this article; the title also uses a word often associated with military jargon (i.e. courage). Thus, this article and others like it depict Sweden as a society that has failed to integrate its immigrant population or to become multi-ethnic in the true sense of the word. Against this backdrop, the articles in the data corpus argue that it would be both inappropriate and costly to embark on more labor immigration schemes. Settled migrants are described as "a great untapped resource, which it is both humanely and economically indefensible not to make use of" (As stated in the article entitled "Better educated immigrants meet companies'needs" - "Bättre skolade invandrare täcker företagens behov" - published on June 6, 2000 in SvD). In other words, articles like this highlight the societal consequences of the failed integration of settled migrants, given that such a large number of them remain unemployed.

Something else that seems worthy of attention is that most of the newspaper articles analyzed take for granted that migrants should shoulder the burden of the staff crisis the Swedish elderly care sector is facing at present. Thus, in this data corpus, recruitment of settled migrants to the sector is an alternative that is neither questioned nor problematized. The possibility that recruitment efforts could be made to attract ethnic Swedes to the sector goes virtually unmentioned in the material. One of the few articles discussing the assumed difficulties that would arise when trying to attract ethnic Swedes states the following:

The sector where employment is growing the fastest is care for the elderly - and it is expected that by 2050, one in ten Swedes will be older than 80 . Who's going to take care of you when you get old? Demanding that well educated, young Swedes do it would crush their dreams and also be enormously costly to the economy and the public finances. So why not let, say, Filipinos do it? They would earn more than they would have in Manila, and Swedes - old as well as young - would benefit from it. (Article entitled "More immigrants save the Swedish welfare state" - "Fler invandrare räddar svenska välfärdsstaten" - published on May 4, 2008 in DN) 
International Journal of Ageing and Later Life

This excerpt clearly demonstrates the unspoken assumption underlying Swedish daily newspaper reporting on elderly care, namely, that migrants are a better solution to the staffing crisis because it is unrealistic to assume that young ethnic Swedes will want to work in this sector. Young Swedes are depicted as well-educated people with dreams of a better future, while migrants are represented as their opposites. Migrants are described as people who could "benefit" if they were to join the elderly care sector, while ethnic Swedes are depicted as people whose dreams would be shattered if they were to become care workers. As such, migrants are represented as people who would not only be grateful to come to Sweden, but who would also appreciate getting work within the care sector. Describing migrants as "guardian angels" who are "helping" the sector overcome its staffing shortage, and as people who can "solve the crisis," "save elderly care," and "save the Swedish welfare state," this extract (and the data corpus as a whole) reminds us of Narayan's argument that "care discourse runs (not only) the risk of being used to ideological ends," but also in "self-serving ways by the dominant and the powerful" (1995: 136).

\section{Migrant Care Workers: Proficient in Other Languages, Highly Motivated to Work in the Sector and Well Suited to Offering Culture-Appropriate Care}

Nordberg (2016) ended her analysis of the Finnish media imagery on migrant care workers by alluding to the fact that the daily newspaper reporting she focuses on (2003-2013) seems to be characterized by ambiguity. On the one hand, migrant care workers are depicted in her data corpus as "entrepreneurial, skillful, and flexible labor force," while, on the other, they are depicted as "childish family-oriented women who are out of place" (Nordberg 2016: 112). Although the Swedish media do not refer to migrant care workers in the same manner, we recognize that Swedish media representations can in part be described as containing ambiguity. This is particularly evident when we look specifically at the proportion of articles explicitly alluding to the actual characteristics and skills attributed to migrant care workers. Table 3 shows that the vast majority of articles do not explicitly state what it is these workers will bring to the elderly care sector (71.6\% of the newspaper articles analyzed do not make explicit allusions 
Migrant care workers in elderly care

Table 3. Characteristics and skills migrant care workers are believed to have $(n=370)$

\begin{tabular}{lc}
\hline Proficiency in other languages & $10.3 \%(38)$ \\
High motivation to work in elderly care & $6.8 \%(25)$ \\
Possession of occupational knowledge from their home country & $2.4 \%(9)$ \\
A special respect for and ability to take care of the elderly & $2.1 \%(8)$ \\
Abilities to act with authority and make quick decisions & $0.3 \%(1)$ \\
Fast learners who adapt easily to Swedish working conditions & $0.3 \%(1)$ \\
Entrepreneurial interest in establishing multicultural nursing homes & $0.3 \%(1)$ \\
Unspecified skills & $5.9 \%(22)$ \\
Not stated & $71.6 \%(265)$ \\
Total & $100 \%(370)$ \\
\hline
\end{tabular}

to skills and/or characteristics they are thought to have). When newspaper articles note something in particular, it is sometimes their proficiency in other languages that is mentioned $(10.3 \%$ of the articles in the data corpus do this), and that they are believed to be highly motivated to work in this sector $(6.8 \%$ of the articles refer to this). With regard to their proficiency in other languages (other than Swedish), it seems relevant to mention that the proportion of people born abroad in the $65+$ population in Sweden has steadily increased over the past two decades. According to national statistics, $20 \%$ of Sweden's population belongs to the $65+$ category. The percentage of people in this category that was born abroad (which is the category Statistics Sweden uses) has risen from 9\% in 2001 to 13\% at the end of 2018 (SCB 2018). Thus, the media representations of migrant care workers that do allude to specific skills these workers have seem to be referring to the fact that caring for elderly people with diverse ethno-cultural backgrounds is one of the future challenges the welfare sector will face.

Table 3 also shows that few articles make explicit allusions to these workers' caring skills (only 2.1\% of the articles during this period do so). However, a look at the part of the data corpus that focuses on culture-appropriate care $(n=157)$ shows a slightly different picture, in that $24.2 \%$ of the newspaper articles focusing on this issue give the impression that migrants are better suited to caring for migrants (see Table 4). Thus, we need to take a closer look at what the qualitative content analysis shows. One of 
International Journal of Ageing and Later Life

Table 4. Suitability claims made in the articles that explicitly address culturally appropriate care $(N=157)$

\begin{tabular}{lc}
\hline $\begin{array}{l}\text { Who is referred to as the best provider of elderly care in the } \\
\text { articles discussing culture-appropriate care? }\end{array}$ & $\%$ \\
\hline $\begin{array}{l}\text { Migrants are best suited to providing care to migrants } \\
\text { Migrants are best suited to providing care for non-migrants } \\
\text { (ethnic Swedes) }\end{array}$ & $3.2 \%(5)$ \\
$\begin{array}{l}\text { Migrants are not suited to providing care for non-migrants } \\
\text { (ethnic Swedes) }\end{array}$ & $2.5 \%(4)$ \\
$\begin{array}{l}\text { Both migrants and non-migrants are suited to providing } \\
\text { care for migrants }\end{array}$ & $0.6 \%(1)$ \\
$\begin{array}{l}\text { Non-migrants (ethnic Swedes) are best suited to providing } \\
\text { care for migrants }\end{array}$ & $1.3 \%(2)$ \\
Not stated & $68.2 \%(107)$ \\
Total & $100 \%(157)$ \\
\hline
\end{tabular}

the articles analyzed focuses on a recruiting program primarily comprising men with a migrant background, who are said to be "a very deserving group" (Article entitled "Immigrants solve labor shortage" - "Invandrare löser arbetskraftsbrist" - published on June 6, 2000 in SvD). A man from Somalia, who is described as being dedicated to his family and children and as someone who speaks positively about Swedish elderly care, is the focus of this article. Although he was originally a technician and has no previous experience of the Swedish job market, he is quoted as saying that he has always wanted to work with people, especially older people. In addition, this particular newspaper article claims that men with migrant backgrounds who are looking for work "come from cultures with a tradition of the man carrying a great responsibility for supporting the family" (Article entitled "Immigrants solve labor shortage" - "Invandrare löser arbetskraftsbrist" - published on June 6, 2000 in SvD). In another article, the focus is on a Swedish care recipient with experience of care staff from various ethnic backgrounds. This article stated the following:

The home-help workers she appreciates the most are people from countries and parts of the world that are far away, from cultures where people are used to respecting older 
Migrant care workers in elderly care

people, whereas the home-help workers that she feels stress too much and are too impersonal in their treatment are often native Swedes. (Article entitled "118 Home-help workers in two years" - "118 hemvårdare på två år" - published on August 3, 2002 in SvD)

In this excerpt, migrant care workers are juxtaposed to their Swedish counterparts. By describing migrant workers as people who are respectful and understanding of older people, this article (and others like it) make an implicit assumption that ethnic Swedes do not share these values. Another article states that these workers come from countries "where it is self-evident that the young should take care of the old; anything else would be shameful. But here in Sweden, the young don't have the time that's needed" (Article entitled "Safe in a Spanish environment" - "Trygga i spansk miljö" - published on April 23, 2003 in SvD). A similar statement is made in another article: "the respect that older people are accorded is far greater in Africa than it is in, for example, Europe" (Article entitled "Mugabe's faux pas brings hope" - "Mugabes fadäs ger hopp" - published on February 21, 2015 in SvD). Thus, the constant comparison - in explicit or subtle ways - of migrant care workers to Swedes to workers without these backgrounds is one of the ways in which these newspaper articles convey the notion that migrant workers are an asset to the sector. In another article, the relative of an older person receiving care from such a worker explains that they are "dedicated people who are there for you, treat the elderly with love and care, work a double shift if there's not enough staff, sign up to work at Christmas and New Year" (Article entitled "On class, hate and love" - "Om klasshat och kärlek" published on May 31, 2003 in SvD). The relative interviewed claims to have had completely different experiences with Swedish staff, describing them as workers who "seem to lack all interest, they watch TV instead of talking with the elderly, sit there, apathetic and passive, call in sick at the last minute even when they're well". (Article entitled "On class, hate and love" - "Om klasshat och kärlek" - published on May 31, 2003 in SvD).

As mentioned, migrants' language abilities are especially important against the backdrop of the debate on culture-appropriate care that has taken place within Swedish elderly care since the mid-1990s, as shown in Table 1 (cf. Torres 2006b). Thus, both the increased diversity of elderly care recipients and the debate on culture appropriateness prompted by this diversity have provided the context in which the explicit representation 
International Journal of Ageing and Later Life

of migrant care workers as culture- and language-competent caregivers takes shape. In one of the articles analyzed, one of the migrant care workers working in a Spanish-speaking Latin-American nursing home describes why care recipients with migrant backgrounds would want to be cared for by a migrant care worker:

After all, it's not just the language that we have in common with those at the home. We also understand each other because we come from the same culture and have had similar experiences. (Article entitled "Safe in a Spanish environment" - "Trygga i spansk miljö" - published on April 23, 2003 in SvD)

In this excerpt, we see how the daily newspaper reporting assumes that having the same background is crucial if care recipients and care providers are to understand one another. Thus, some of the analyzed material assumes that no one could be a better caregiver for an elderly care recipient with a migrant background than a person who him-/herself has a migrant background, preferably one who comes from the same culture and speaks the same language. The fact that they are sometimes assumed to come from cultures that value old age is part of the explicit representation of these workers not only as skillful caregivers but also as care workers who can provide culture-appropriate care. In contrast, care staff with a Swedish background are depicted as not understanding culture-based needs, even though they do their best to consider care recipients' cultural backgrounds. One of the articles analyzed states: "misunderstanding is a great problem in the care of older immigrants" (Article entitled "Compatriots best for old immigrants" - "Landsmän bäst för gamla invandrare" - published on December 14, 2000 in SvD). The same article exemplifies this using a story about an older Iranian man, whose bed the Swedish staff had forgotten to lower. To make it easier to visit the bathroom without stumbling from the high bed, which would have unpleasant consequences, the man decided to take out the mattress and lie on the floor. However, the Swedish staff could not understand what the man was trying to do. Instead of adjusting his bed, they began to care for him on the floor, with considerable difficulty, in an effort to respect his cultural lifestyle and tradition, assuming that he was on the floor because, as a Muslim, he would probably want to pray. 
Migrant care workers in elderly care

Thus, the data corpus analyzed suggests that Swedish care providers face difficulties, not only because they are not particularly skillful at caring but also because they lack the ability to provide care that is culturally appropriate.

In another article, we find the following statement: "Many elderly immigrants do not apply for home-help care or for elderly care because of language or cultural differences/.../ they worry about having a homehelp care worker who does not speak their language" (Article entitled "Elderly immigrants do not seek care" - "Äldre invandrare söker inte vård" - published on August 23, 2003 in SvD). Thus, just as bilingualism and communicative competence distinguish migrant care workers from care workers who are ethnic Swedes, care recipients with migrant backgrounds are described as people who want to receive care in their mother tongue and/or want to be cared for in a culture-appropriate way. Thus, articles addressing the potential difficulties migrant care workers could face are more the exception than the rule. Table 4 shows, for example, that only $3.2 \%$ of the articles making suitability claims allude to migrants being best suited to providing care for nonmigrants, while only $2.5 \%$ allude to them not being able to provide such care. However, let us take a closer look at an article from 2005 entitled "Older people who do not want to be cared for by people with migrant backgrounds" (published on February 8, 2005 in SvD); this is one of the articles hinting at some of the challenges migrant care workers may face. This article refers to a radio program that caused a scandal within the sector. In the program, 20 care homes and home-help care units were called by a radio reporter who pretended to be a family member of an older Swede who did not want to have his/her older relative cared for by a migrant care worker. The vast majority of the care facilities called (i.e. 16 out of the 20) said that this could be arranged (see Jönson 2007, who studied this very case). The 2005 article quotes the then Minister of Elderly Care saying that she finds it "unacceptable that older people are allowed to reject a person with a foreign background" (Jönson 2007). However, articles like this one are not common in this data corpus. In other words, the issues of recruitment of migrant care workers to the Swedish elderly care sector and their situation once in it are seldom addressed and/or problematized in the daily newspaper reporting analyzed. 
International Journal of Ageing and Later Life

\section{Discussion}

The content analysis presented here reveals that the Swedish newspaper representations of migrant care workers analyzed in the present project rely on four ideas: (1) that migrant care workers are the solution to the labor shortage the elderly care sector is experiencing; (2) that these workers are proficient in other languages; (3) that they are highly motivated to work in this sector; and (4) that they are well-suited to offering culture-appropriate care to Sweden's ethno-cultural minorities. The fact that some of these representations portray these workers as particularly skillful is in accordance with the only previous study on media representations of migrant care workers we could find (e.g. Weicht 2010). One of the key ideas in the representations presented here is that migrants come from cultures that are "used to respecting older people" and "where it is self-evident that the young should take care of the old." Thus, portrayed as naturally gifted caregivers, migrant care workers are depicted as people who have a lot to offer the elderly care sector. Research on cross-cultural interaction within Swedish long-term care facilities suggests that the representations analyzed here resonate well with the ways in which migrant care workers working in Swedish nursing homes are viewed. The assumption that these workers are naturally gifted caregivers has been found to affect the division of labor within nursing homes and create unbalanced care loads between workers (e.g. Torres 2010). Thus, we suggest that the representations our analyses have shed light on could have implications for everyday interaction within the Swedish elderly care sector.

Comparisons to Nordberg's (2016) analysis of Finnish media imagery concerning migrant care workers can readily be made here. Nordberg (2016) noted, for example, that the Finnish media imagery concerning migrant care workers depicts them as disciplined, hardworking, and as people "with a strong repertoire of flexible strategies on how to manage their wealth and well-being in relation to a distant 'real home'" (Nordberg 2016: 111). Although the idea that migrant care workers are hardworking is also found in our material, the notion that they are "agents selling their labor to the Finnish welfare state, compensated by money transfers" is not part of the Swedish public discourse. This may be because most of our data corpus is more focused on settled migrants than on attracting 
workers from abroad to the sector. Irrespective of why this is the case, we note that comparisons between migrants and Swedes are sometimes used in the newspaper articles analyzed here. We also note that allusions to migrant care workers being particularly skillful at caring and especially well equipped to care for people who, like themselves, have a migrant background are among the reasons often offered to suggest that these workers are an asset to the Swedish elderly care sector.

The idea that migrant care workers are particularly well equipped to provide culture-appropriate care builds on the notion that they have language competences that would benefit the sector at present, when Sweden's older population is more culturally and ethnically diverse. Curiously enough, the representations in question never ask whether these workers' language skills actually match the sector's needs. Two facts - that the vast majority of people these workers actually care for speak Swedish and that migrants' language skills are not really needed everywhere in Sweden are never discussed (we make this claim because migrants tend to mostly reside in the bigger cities). Thus, migrant care workers are depicted both as the general solution to the sector's staffing shortage and as a particular solution for the few who will need language-specific care in the future. It is for this reason that we suggest that the representations presented here seem to be a prime example of how the fine line between acknowledging challenges and failing to identify new ones can be discursively managed. The articles analyzed here never explicitly address the implications recruitment of migrant care workers could have for the majority of care recipients (i.e. native Swedes). By failing to do this, these newspaper articles do not consider how their own line of reasoning could be used to argue that recruiting migrant care workers to the sector could entail offering culture-incompetent care to native Swedes. The material does not acknowledge research showing that migrant care workers working in Swedish nursing home settings often feel less respected by residents and their families than native workers do, and that they report experiencing racism directed at them by both elderly patients and their family members (Olt et al. 2014).

The idea that migrant care workers are the solution par excellence to the staffing crisis the elderly care sector faces is in line with the literature presented in the section on research on migrant care workers 
International Journal of Ageing and Later Life

(e.g. Lowell et al. 2010; Walsh \& Shutes 2012). In the newspaper articles analyzed here, migrant care workers are frequently described as "guardian angels" who could rescue the Swedish elderly care sector from its crisis, or as "a reserve army" that this sector has yet to tap into. These representations help to convey the message that migrant care workers are the obvious solution to the sector's staffing crisis. Irrespective of whether or not the newspaper articles focused on settled but unemployed migrants, or on importing migrants to the sector, this representation takes for granted that recruiting migrants to the sector is a win-win situation. Migrants are described as people who not only need to work but who are grateful for a chance to enter the Swedish labor market. However, the staffing crisis the elderly care sector is experiencing is discussed in two different ways. First, a growing number of older people will need help in the future, and the number of staff needed to meet their needs must increase. Second, the kind of work the sector offers is not attractive, so finding people who would be interested in it is not going to be easy. As one of the articles put it, helping older people is not necessarily the kind of work people "dream" of having. According to another article, the prospect of such work is a "dream crusher" for some. This is interesting, considering findings showing that media representations can influence how people think about topics they know little about. In this respect, we draw attention to Robinson's (2006) argument, which is that when we call attention to care discourses, we tend to reveal that "the values and work associated with care and caring are undervalued and under-resourced globally" (Robinson 2006: 8). The fact that some of these newspaper articles describe the elderly care sector as one in which young ambitious people would not want to work (i.e. as a dream crusher) is a prime example of how undervalued the sector seems to be. For this reason, the material analyzed here reminds us of Tronto's (2010) argument that the fact that "care is still disproportionately the work of the less well-off and more marginal groups in society reflects care's secondary status in society" (Tronto 2010: 166).

Some of the explicit references to migrant care workers' skill set (albeit uncommon in the material as a whole) remind us of one of Tronto's (1993) first contributions to the ethics of care debate, in which she argued that we need to inquire into what she calls "privileged irresponsibility" (Tronto 1993: 120-121), that is, the fact that some people can pass on their caring responsibilities to others. In her latest contribution to this debate, 
she has developed this idea further, arguing that we need to deconstruct the ways in which the powerful argue that "some people have to take up their caring responsibilities while others are given 'passes' out of such responsibilities" (Tronto 2013: 33). Our analysis has tapped into this very angle by showing how daily newspaper reporting on elderly care in Sweden hands out such passes through its descriptions of migrants and Swedes as each other's caring opposites. In the material, it was not uncommon to refer to ethnic Swedes in ways that suggest they "are given passes because they are engaged in other activities that they (and presumably society) deem to be simply more important than caring" (Tronto 2013: 33). Migrants, in contrast, are portrayed as not only needing, but also wanting, to take on Swedes' caring responsibilities. This remind us of Narayan (1995), who has warned us that care discourse can be used in "self-serving ways."

The newspaper reporting analyzed here relies on the constant juxtaposition of migrant care workers with ethnic Swedes by implying that migrants have modest dreams, are more reliable workers, have innate caregiving skills, and come from cultures that have respect for elderly people and that they can, therefore, naturally provide culture-appropriate care. For this reason, we propose that the media representations analyzed here depict migrant care workers as "particular Others" (cf. Narayan 1995) who are an asset to the sector merely because they are assumed to be different from the majority population, that is, the general us that the newspaper articles never really address, but that is the backdrop against which these representations are constructed. This is why these representations can be regarded as a double-edged sword, because while migrant care workers are depicted as assets to the sector, their "Otherness" seems to be the very reason why they are also depicted as the "reserve army" ("reserve" being the adjective worth noting).

Last but not least, we would like to draw attention to Tronto's (2013) argument that the ethics of care lens allows us to see the ways in which "more powerful people can fob the work of care onto others: men to woman, upper to lower classes, free men to slaves, those that are considered racially superior to those whom they consider racially inferior people" (Tronto 2013: 105-106). The newspaper articles analyzed here clearly depict migrant care workers in ways that serve the needs of the Swedish elderly care sector - a sector that is trying to attract these workers while 
International Journal of Ageing and Later Life

fobbing the country's older population's care needs onto them. As such, these media representations provide us with an unsettling glimpse not only into how Swedish media view "the Other" but also into how the rationale is used to fob care onto them (Torres 2017). In this connection, the present article raises questions about Sweden's capacity to become a caring democracy of the type that Tronto (2013) argued must be the way forward for welfare states. She contends that these welfare states need to "figure out how to put responsibilities for caring at the center of their democratic political agendas" (Tronto 2013: ix). We argue that when we use the ethics of care lens to look at media representations - as we have done here - we can shed light on a society's moral backbone. The picture of Sweden painted by the daily newspaper reporting on elderly care analyzed here is troubling to say the very least, as far as "particular Others" are concerned. The finding that care work appears to be so undervalued in these media representations is part of the reason why we question whether Sweden can be regarded as a caring democracy.

\section{Acknowledgements}

The authors gratefully acknowledge that this study is part of a project comparing Finnish and Swedish daily press reporting on elder care, which was originally designed by the first author (i.e. Prof. Sandra Torres who has also led the project in Sweden) and Dr. Camilla Nordberg (Helsinki University; who has led the Finnish part of the project). This article is based on data that have been collected and analyzed by the second author (i.e. Dr. Jonas Lindblom). His work has benefitted from holding time-limited research-based positions made possible by the funding that the Faculty of Social Sciences of Uppsala University awarded to Prof. Torres. Thus, the authors are grateful for this funding, as well as for the constructive comments they received on earlier versions of this article from the Welfare Research Group at the Dept. of Sociology of Uppsala University.

\section{Corresponding Author}

Sandra Torres, Department of Sociology, Uppsala University, Box 624, SE751 26, Uppsala, Sweden. Email: sandra.torres@soc.uu.se 
Migrant care workers in elderly care

\section{References}

Barnes, M., Brannelly, T., Ward, L. \& Ward, N. (eds.) (2015). Ethics of Care: Critical Advances in International Perspective. Bristol: Policy Press.

Bettio, F., Simonazzi, A. \& Villa, P. (2006). Change in care regimes and female migration: The "care drain" in the Mediterranean. Journal of European Social Policy 16(3): 271-285.

Bourgeault, I. L., Atanackrovic, J., Rashid, A. \& Parpia, R. (2010). Relations between immigrant care workers and older persons in home and longterm care. Canadian Journal of Aging 29(1): 109-118.

Brown, P. (1995). Prejudice: It's Social Psychology. Oxford, UK \& Cambridge, USA: Blackwell.

Browne, C. V. \& Braun, K. L. (2008). Globalization, women's migration, and the long-term care workforce. The Gerontologist 48(1): 16-24.

Bryman, A. (2006). Mixed Methods. Thousand Oaks: Sage Publications.

Cresswell, J. W. (1998). Qualitative Inquiry and Research Design: Choosing Among Five Traditions. London: Sage Publications.

Di Rosa, M., Melchiorre, M. G., Lucchetti, M. \& Lemura, G. (2012). The impact of migrant work in the elder care sector: Recent trends and empirical evidence in Italy. European Journal of Social Work 15(1): 9-27.

Doyle, M. \& Timonen, V. (2009). The different faces of care work: Understanding the experiences of the multi-cultural care workforce. Ageing $\mathcal{E}$ Society 29: 337-350.

Doyle, M. \& Timonen, V. (2010). Obligations, ambitions, calculations: Migrant care workers' negotiation of work, career and family responsibilities. Social Politics 17(1): 29-52.

Elrick, T. \& Lewandowska, E. (2008). Matching and making labor demand and supply: Agents in Polish migrant networks of domestic elderly care in Germany and Italy. Journal of Ethnic and Migration Studies 34(5): 717-734.

Ferguson, R. (1998). Representing "Race": Ideology, Identity and the Media. New York: Arnold.

Gale, P. (2004). The refugee crisis and fear: Populist politics and media discourse. Journal of Sociology 40(4): 321-340.

Hochschild, R. (2000). Global care chains and emotional surplus value. In V. Hutton \& A. Giddens (eds.), On the Edge: Living with Global Capitalism (pp. 130-46). London: Jonathan Cape. 
International Journal of Ageing and Later Life

Iecovich, E. (2007). Client satisfaction with live-in and live-out home care workers in Israel. Journal of Aging \& Social Policy 19(4): 105-122.

Iecovich, E. (2010). Tasks performed by primary caregivers and migrant live-in homecare workers in Israel. International Journal of Ageing and Later Life 5(2): 53-75.

Iecovich, E. (2011). What makes migrant live-in home care workers in elder care be satisfied with their job? The Gerontologist 51(5): 617-629.

Jönson, H. (2007). Is it racism? Skepticism and resistance towards ethnic minority care workers among older care recipients. Journal of Gerontological Social Work 49(4): 79-96.

Kilkey, M., Lutz, H. \& Palenga-Möllenbeck, E. (2010). Introduction: Domestic and care work at the intersection of welfare, gender and migration regimes: Some European experiences. Social Policy \& Society 9(3): 379-384.

Leeson, G. (2010). Migrant carers: Saving or sinking the sustainability of eldercare? Population Ageing 3: 1-6.

Lindblom, J. \& Torres, S. (2011). Etnicitets-och migrationsrelaterade frågor inom äldreomsorgen: En analys av SvD:s rapportering mellan 19952008 [Ethnicity- and migration-related issues in elderly care: An analysis of a Swedish daily newspaper from 1995-2008]. Socialvetenskaplig tidskrift 18(3): 222-243.

Lowell, B. L., Martin, S. \& Stone, R. (2010). Aging and care giving in the United States: Policy contexts and the immigrant workforce. Population Ageing 3: 59-82.

Lutz, H. \& Palenga-Möllenbeck, E. (2010). Care work migration in Germany: Semi-compliance and complicity. Social Policy \& Society 9(3): 419-430.

McGregor, J. (2007). Joining the BBC (British Bottom Cleaners)': Zimbabwean migrants and the UK care industry. Journal of Ethnic and Migration Studies 33(5): 801-824.

Narayan, U. (1995). Colonialism and its others: Considerations on rights and care discourses. Hypatia 10(2): 133-140.

Neuendorf, K. (2002). The Content Analysis Guidebook. Thousand Oaks, CA: Sage.

Nordberg, C. (2016). Outsourcing equality: Migrant care worker imaginary in Finnish media. Nordic Journal of Working Life Studies 6(3): 101-118. 
Olt, H., Jirwe, M., Saboonchi, F., Gerrish, K. \& Emami, A. (2014). Communication and equality in elderly care settings: Perceptions of first- and second generation immigrant, and native Swedish healthcare workers. Diversity and Equality in Health and Care 11: 99-111.

Olthuis, G., Kohlen, H. \& Heier, J. (2014). Moral Boundaries Redrawn: The Significance of Joan Tronto's Argument for Political Theory, Professional Ethics, and Care as Practice. Leuven, Belgium: Peeters Publishers.

Pfau-Effinger, B. \& Rostgaard,T. (2011). Care between Work and Welfare in Europe. Houndsmills: Palgrave Macmillan.

Raijman, R., Schammah-Gesser, S. \& Kemp, A. (2003). International migration, domestic work and care work: Undocumented Latina migrants in Israel. Gender \& Society 17(5): 727-749.

Robinson, F. (2006). Care, gender and global social justice: Rethinking ethical globalization. Journal of Global Ethics 2(1): 5-25.

Shutes, I. \& Walsh, K. (2012). Negotiating user preferences, discrimination, and demand for migrant labour in long-term care. Social Politics 19(1): 78-104.

Silverman, D. (2001). Interpreting Qualitative Data: Methods for Analysing Talk, Text and Interaction. London, Thousand Oaks \& New Delhi: Sage.

Statistiska centralbyrån (SCB) (2018). Folkmängd efter födelseregion, ålder och kön: år 2019-2120. [Population by region of birth, age and gender: 20192120]. Statistikdatabasen. Available on www.statistikdatabasen.scb.se/ pxweb/sv/ssd/?rxid=cf-da-dff-bc-aa-edeb. (Accessed: January 2020)

Stevens, M., Hussein, S. \& Manthorpe, J. (2012). Experiences of racism and discrimination among migrant care workers in England: Findings from a mixed-methods research project. Ethnic and Racial Studies 35(2): 259-280.

Timonen, V. \& Doyle, M. (2010) Caring and collaborating across cultures? migrant care workers' relationships with care recipients, colleagues and employers. European Journal of Women Studies 17(1): 25-41.

Torres, S. (2006a). Culture, migration, inequality and "periphery" in a globalized world: Challenges for the study of ethno- and anthropo-gerontology. In J. Baars, D. Dannefer, C. Phillipson \& A. Walker (eds.), Aging, Globalization and Inequality: The New critical Gerontology (pp. 231-244). Amityville, NY: Baywood Publishing Company.

Torres, S. (2006b). Elderly immigrants in Sweden: Otherness under construction. Journal of Ethnic and Migration Studies 32(8): 1341-1358. 
International Journal of Ageing and Later Life

Torres, S., Lindblom, J. \& Nordberg, C. (2014). Daily newspaper reporting on elderly care in Sweden and Finland: a quantitative content analysis of ethnicity- and migration-related issues, Vulnerable Groups $\mathcal{E}$ Inclusion, 5:1, https://doi.org/10.3402/vgi.v5.21260

Torres, S. (2010). Invandrarskap och tvärkulturella äldreomsorgsmöten [Ethnic otherness and cross-cultural interaction in elderly care]. In S. Johansson (red.) Omsorg och maingfald [Social Care and Diversity] (pp. 67-88). Malmö: Gleerups.

Torres, S. (2013). Transnationalism and the study of aging and old age. In C. Phellas (ed.) Aging in European Societies (pp. 267-281). New York: Springer.

Torres, S. (2017). Fobbing care work unto the "Other": What daily press reporting shows. Sociologisk Forskning (Special Issue: "Look at what's happening in Sweden") 4: 319-322.

Torres, S., Lindblom, J. \& Camilla Nordberg (2012). Medierepresentationer av etnicitet och migrationsrelaterade frågor inom äldreomsorgen i Sverige och Finland. [Media representations of ethnicity- and migration-related issues within elderly care in Sweden and Finland.] Sociologisk forskning 49(4): 283-304.

Tronto, J. C. (1987). Beyond gender difference to a theory of care. Signs: Journal of Women in Culture and Society 12(4): 644-663.

Tronto, J. C. (1993). Moral Boundaries: A Political Argument for an Ethic of Care. London \& New York: Routledge.

Tronto, J. C. (1995). Care as a basis for radical political judgements. Hypatia 10(2): 141-149.

Tronto, J. C. (2010). Creating caring institutions: Politics, plurality and purpose. Ethics and Social Welfare 4(2): 158-171.

Tronto, J. C. (2013). Caring Democracy: Markets, Equality and Justice. New York: University Press.

Van Dijk, T. A. (1987). Communicating Racism: Ethnic Prejudice in Thought and Talk. Newbury Park, Beverly Hills, London \& New Delhi: Sage Publications.

Wall, K. \& Nunes, C. (2010). Immigration, welfare and care in Portugal: Mapping the new plurality of female migration trajectories. Social Policy \& Society 9(3): 397-408.

Walsh, K. \& O'Shea, E. (2010). Marginalised care: Migrant workers caring for older people in Ireland. Population Aging 3: 17-37. 
Walsh, K. \& Shutes, I. (2012). Care relationships, quality of care and migrant workers caring for older people. Ageing $\mathcal{E}$ Society 33(3): 393-420.

Weicht, B. (2010). Embodying the ideal carer: The Austrian discourse on migrant carers. International Journal of Ageing and Later Life 5(2): 17-52.

Wood, N. \& King, R. (2001). Media and migration: An overview. In R. King $\&$ N. Wood (eds.), Media and Migration: Constructions of Mobility and Difference (pp. 1-22). London \& New York: Routledge.

Yeates, N. (2004). Global care chains: Critical reflections and lines of inquiry. International Feminist Journal of Politics 6(3): 369-391. 
